\title{
Preliminary assessment on Agrobacterium-mediated transformation of Dendrobium Broga Giant orchid's PLBs
}

\author{
Jasim Uddain ${ }^{1,2}$, Latiffah Zakaria1, Chew Bee Lynn', Sreeramanan Subramaniam ${ }^{1 *}$ \\ ${ }^{1}$ School of Biological Sciences, Universiti Sains Malaysia, Georgetown, 11800 Penang, Malaysia; ${ }^{2}$ Department of Horticulture, Sher-e-Bangla \\ Agricultural University, Dhaka, Bangladesh
}

\section{A B S TR A C T}

\begin{abstract}
Dendrobium Broga Giant (Dendrobium Bobby Messina $\times$ Dendrobium superbiens) is a newly introducing hybrid orchid species in Malaysia. Suitable target explants potentiality determination is very important before transformation studies. Bacterial chemotaxis and transient $g u s A$ expression were studied using explants as PLBs of Dendrobium Broga Giant to evaluate the capability of bacterial-PLBs interaction during transformation period. Agrobacterium tumefaciens showed positive chemotactic response and their attachment to the PLBs whereas E. coli responded negatively. Mild wounded PLBs displayed higher Agobacterium motility compared to other treatments. Mild wounded PLBs immersed for 15 minutes on the Agrobacterium suspension $\left(\mathrm{OD}_{600 \mathrm{~nm}} \mathrm{O} .8\right.$ ) and co-cultivated for 2 days in co-cultivation media supplemented with $200 \mu \mathrm{M}$ acetosyringone showed highest transient gusA gene expression in Dendrobium Broga Giant orchid. Hence, we concluded that positive chemotactic responses and transient gusA gene expression ability indicate the Dendrobium Broga Giant (DBG) orchid PLBs are a potential target explants for Agrobacterium-mediated genetic transformation studies.
\end{abstract}

Keywords: Dendrobium Broga Giant; Agrobacterium; Chemotaxis; Transient gusA; SEM

\section{INTRODUCTION}

Orchid is an important group of ornamental plants comprising of several thousand species and hybrid. Orchids are valuable ornamentals and have become the second largest cut flowers and potted floricultural crop (Hossain et al., 2010). Malaysia export orchids such as Dendrobium as a cut-flower mostly to Thailand and Philippines. From orchids, Malaysia earn RM 150 million per year which representing approximately $40 \%$ of the total floriculture production (Ahmad et al., 2010).

Biotechnological tools are essential for selecting, analyzing, reproducing and improving the plants (Khan et al., 2009; Khan et al., 2012). Genetic engineering is a breeding approach which assures to avoid the problems by transfer genetic materials with specific traits (Awan et al., 2015). Agrobacterium-mediated transformation offers a promising opportunity in the expansion of specific orchid traits due to cost and time efficiency (Teixeira da Silva et al., 2011). Agrobacterium-mediated transformations confine the natural infection mechanism of Agrobacterium tumefaciens towards the wounded plant tissues and resulting, creates a neoplastic growth disease which is called the crown gall (Teixeira da Silva et al., 2011). The Agrobacterium-mediated genetic transformation process relies both on the activity of the bacterial virulence proteins which are required for the early stages of the transformation process (Citovsky et al., 2007).

Chemotaxis is the movement or direction of an organism or cell in chemicals either toward movement which called positive chemotaxis or away movement from the chemical stimulus which called negative chemotaxis. Bren and Eisenbach (2000) reported that bacterial chemotaxis is a mechanism which responds efficiently and swiftly to changes chemical composition in their environment (Terry et al., 2005; Gnasekaran et al., 2014). Sreeramanan et al. (2006) highlighted that bacterial chemotaxis is considered as the first stages of relations between Agrobacterium and plant cell through the process of bacterial infection. Lux and Shi (2004) reported that bacterial chemotaxis signal transduction pathway mainly depends on three fundamental elements such as signal reception by chemoreceptor which was located on the cell membrane after that membrane

\footnotetext{
${ }^{*}$ Corresponding author:

Sreeramanan Subramaniam, School of Biological Sciences, Universiti Sains Malaysia, Georgetown, 11800 Penang, Malaysia.

E-mail: sreeramanan@gmail.com
} 
receptors convey that signal to the motor and finally sensor that signal for adaptation and desensitization. Chemotaxis function also depends on sensor kinase gene che $A$ which interrelated with MCPs and two separate response of CheY1 and CheY2 regulatory gene which was located within the che operon (Merritt et al., 2007). Swimming motility of bacteria makes an essential quantitative part to virulence in near the beginning stages of host invasion and colonization (Tans-Kersten et al., 2001). The Agrobacterium capability to interact with the host is highly influenced by their motility (Merritt et al., 2007). Therefore, it is crucial to determine the Agrobacterium behaviour and motility before attempting any transformation process. Chemotaxis assay is a method to measure the bacteria-plant interaction and the bacterial motility by using a simple swarm plate agar protocol (Sreeramanan et al., 2009).

Transient gus $A$ expression is an indicator of gene transfer and expression efficiency for the optimization of Agrobacterium-mediated transformation protocols which is coding for the enzyme $\beta$-glucoronidase (GUS) used as a reporter gene to identify the transgenic plants. Several factors such as types of wounding, bacterial immersion period, co-cultivation period, density of Agrobacterium $\left(\mathrm{OD}_{600 \mathrm{~nm}}\right)$ and acetosyringone concentrations in cocultivation medium which are essential for transformation studies.

Agrobacterium tumefaciens attached efficiently to the host plant through initiating infection. Orchids like other monocots are not natural hosts for Agrobacterium. The purpose of Agrobacterium attachment on plant cell is consequently important to substantiate Agrobacterium interaction on monocot cells before attempting transformation. Hence, attachment of Agrobacterium to plant cells can be observed during chemotaxis and histochemical GUS assays, the specificity of the cell-cell contact would be preferably confirmed by a transient gus $A$ measurement of the binding aptitude of attachment able to bacteria. This present study evaluates the preliminary assessments on Agrobacteriummediated transformation of Dendrobium Broga Giant's PLBs.

\section{MATERIALS AND METHODS}

\section{Plant materials}

Protocorm-like bodies (PLBs) were used as plant materials in this study. Dendrobium Broga Giant orchid PLBs were maintained in half-strength of MS semi-solid medium (Murashige and Skoog, 1962) which was supplemented with $2 \%$ sucrose (w/v) and $1 \mathrm{mg} / \mathrm{LBAP}$ (6-benzylaminopurine) and $\mathrm{pH}$ adjusted to 5.8. The PLBs were incubated at $23 \pm 2^{\circ} \mathrm{C}$ under 16 hours photoperiod for four weeks and sub cultured at least twice prior to use in the following treatments. Three types of wounded PLBs were used in this study. These are, $\mathrm{W}_{0}=$ intact PLBs (control), $\mathrm{W}_{1}=$ Mild wounded; punctured with sterile needle (around 25-30 \%) and $\mathrm{W}_{2}=$ severely wounded PLBs; vertical cut using scalpel (around 50-60\%). Three to four mm size PLBs were used for all treatments.

\section{Bacterial culture}

Agrobacterium tumefaciens (strain LBA4404) which harbouring the pCAMBIA 1304 and E. coli (strain DH5 $\alpha$ ) bacteria harbouring the pMRC 1301 used in this study. Both bacteria were cultured in $50 \mathrm{mg} / \mathrm{L}$ kanamycin containing Luria Bertani (LB) broth medium. The bacteria were grown overnight $\left(28 \pm 2^{\circ} \mathrm{C}\right)$ at $120 \mathrm{rpm}$ under dark condition. The bacterial culture was streaked on $50 \mathrm{mg} / \mathrm{L}$ kanamycin containing LB agar medium and incubated for 2 days at $28 \pm 2^{\circ} \mathrm{C}$ under dark conditions for bacterial single colonies. Bacterial single colonies were suspended into $30 \mathrm{ml} \mathrm{LB}$ broth containing $50 \mathrm{mg} / \mathrm{L}$ kanamycin $\left(28 \pm 2^{\circ} \mathrm{C}\right)$ at $120 \mathrm{rpm}$ under dark conditions for overnight. The optimal density $\left(\mathrm{OD}{ }_{600 \mathrm{~nm}}\right)$ of the bacteria suspension was adjusted to 0.8 throughout in this study.

\section{Chemotaxis assay}

The Chemotaxis assays were conducted according to Shaw's swarming agar plate method (Shaw, 1995). The chemotactic medium contained $10 \mathrm{mM}$ potassium phosphate buffer which contain $\mathrm{pH} 7.0,1 \mathrm{mM}\left(\mathrm{NH}_{4}\right)_{2} \mathrm{SO}_{4}, 1 \mathrm{mM} \mathrm{MgSO}_{4}$, $1 \mathrm{mM}$ potassium- EDTA and $0.3 \%$ bacteriological agar (w/v), topped up with Luria Bertani (LB) broth. The bacterial (A. tumefaciens and E. coli) single colonies were inoculated in the central point of the petri dishes via a sterilized $1000 \mu \mathrm{L}$ pipette tips. PLBs were cultured on media which maintained $2.5 \mathrm{~cm}$ distance from bacterial inoculation point. The inoculated PLBs were incubated at $28 \pm 2^{\circ} \mathrm{C}$ in the dark for 24,48 and 72 hours. Bacterial movement (both towards and backward) from the inoculation point was measured by scale after 24,48 and 72 hours.

\section{Optimization of several transformation parameters}

There are several parameters involved in Agrobacteriummediated transformation system which influences T-DNA transfer to the plant cells. The following parameters were optimized for successful transformation of DBG orchid's PLB: wounding of PLBs $\left(\mathrm{W}_{0}=\right.$ intact PLBs, $\mathrm{W}_{1}=$ mild and $\mathrm{W}_{2}=$ severe $)$; bacterial density $(0.4,0.6,0.8,1.0$ and 1.2 at $\left.\mathrm{OD}_{600 \mathrm{~nm}}\right)$; immersion period $(5,10,15,20,25$ and 30 minutes after inoculation); co-cultivation period (1, 2 , 3,4 and 5 days) and acetosyringone concentration (0, 50, $100,150,200,250$ and $300 \mu \mathrm{M})$. Throughout the course of the optimization study, other transformation factors were kept constant on the basis of preliminary test results while optimizing one particular factor. 


\section{Histochemical GUS assay}

All transformation parameters were optimized on the basis of transient GUS expression. Histochemical GUS assay was carried out according to Jefferson et al. (1987) with slight modification. Co-cultured PLBs were incubated overnight in gus buffer [1mg/ml X-Gluc (5-bromo-4-chloro-3-indolyl$\beta$-D-glucuronide); $100 \mathrm{mM} \mathrm{Na} \mathrm{Po}_{4}(\mathrm{pH}-7.0) ; 10 \mathrm{mM}$ $\mathrm{Na}_{2}$ EDTA; $0.5 \mathrm{mM} \mathrm{K}_{3} \mathrm{Fe}(\mathrm{CN})_{6} ; 0.5 \mathrm{mM} \mathrm{K}_{4} \mathrm{Fe}(\mathrm{CN})_{6}$ and $1 \%$ Triton X-100] at $37^{\circ} \mathrm{C}$. PLBs were then transferred to $70 \%$ ethanol for 24 hours to remove chlorophyll. Chlorophyll free PLBs were observed under phase contrast microscope. Completely blue stained PLBs were considered as a transformed PLB (Fig. 1). The following formula was used to determine the transformation frequency:

\section{Transformation frequency $(\%)$}

$=\frac{\text { Number of transformed PLBs }}{\text { Total number of PLBs }} \times 100$

\section{Scanning electron microscopy}

For SEM analysis, PLBs were immersed on both bacterial strain (A. tumefaciens and E. coli) for 15 minutes with $70 \mathrm{rpm}$. After immersion PLBs were blotted by sterile filter paper and cultured on co-cultivation media for two days. Co-cultivated PLBs were used for scanning electron microscopy (SEM) followed by freeze drying method. The freeze drying techniques drawn in vapour fixing on the specimens through $1 \%$ osmium tetroxide designed for one hour. Followed by freeze drying (Emitech K750X model freeze dryer, Emitech Ltd. Kent, USA) the specimens were transfer in liquid nitrogen $\left(-210^{\circ} \mathrm{C}\right)$ slush and coated with 5-10 nm of gold sputter (Polaron SC515 sputter Coater, Fison Instruments, VG Microtech, Susses, UK). The analysis were conducted via Scanning Electron Microscope (Leo Supra 50 VP Field Emission SEM, Carl-Ziess SMT, Oberkochen, Germany) and all images were processed digitally by using microanalysis system software (Oxford INCA 400 energy dispersive $\mathrm{X}$-ray).

\section{Statistical analyses}

All data were calculated by the mean of the three individual experiments. Each experiments were designed in CRD (Complete randomized design) which followed by three replicates. All mean data were analyzed by one way ANOVA via SPSS software version 20. Comparisons of the mean data and standard error (SE) were determined by DMRT (Duncan's multiple range tests) at $\mathrm{p} \leq 0.5$ level of significance.

\section{RESULTS AND DISCUSSION}

\section{Bacterial chemotaxis}

Bacterial single colony cultured on semisolid agar plates for swarming outward from the middle point of inoculation. Bacterial swarming was able to be seen towards the naked eye which was authorized to measure the chemotaxis response of Agrobacterium tumefaciens. Three types of wounded PLBs were used in this experiment and chemotaxis responses were determining 24,48 and 72 hours after inoculation.

The positive chemotaxis behavior was observed in Agrobacterium for all cases. In wounded PLBs, different wounded PLBs significantly responded on the ratio of chemotaxis movement which is ranged from 1.08 to 1.10 units (Fig. 2). Mild wounded ( $\left.\mathrm{W}_{1}\right)$ PLBs showed the highest (1.10) chemotaxis movement whereas the lowest (1.08) chemotaxis movement was observed in severe wounded PLBs $\left(W_{2}\right)$ but statistically no significant differences between intact PLBs $\left(\mathrm{W}_{0}\right)$ and mild wounded PLBs $\left(\mathrm{W}_{1}\right)$ (Fig. 2). Bacterial (Agrobacterium tumefaciens) inoculation time (24, 48 and 72 hours) did not responses significantly on the ratio of chemotaxis movement of Dendrobium Broga Giant orchid PLBs (Fig. 3). The chemotaxis movement ratio after bacterial inoculation time is range from 1.07 to 1.13 units. The maximum (1.13) ratio of chemotaxis movement was recorded from 48 hours after inoculation and the minimum (1.07) ratio was found from 24 hours after inoculations (Fig. 3). In combination of wounded PLBs and bacterial inoculation time significantly responded on the bacterial movement of Dendrobium Broga Giant orchid (Table 1). Mild wounded $\left(W_{1}\right)$ PLBs combined with 48 hours after inoculation time illustrated the highest (1.27) ratio of bacterial movement and the lowest (1.03) ratio was recorded in severe wounded PLBs $\left(\mathrm{W}_{2}\right)$ after 48 hours bacterial inoculations (Table 1$)$. Intact PLBs $\left(\mathrm{W}_{0}\right)$ with 48 hours after bacterial inoculations time and mild wounded PLBs $\left(\mathrm{W}_{1}\right)$ after 72 hours bacterial inoculation showed statistically similar results on mild wounded PLBs $\left(\mathrm{W}_{1}\right)$ with 48 hours after inoculations (Table 1). In all cases, severe wounded PLBs $\left(\mathrm{W}_{2}\right)$ demonstrated the lowest bacterial motility and

Table 1: Combined effects of wounded PLBs and bacterial inoculation time on chemotaxis movement of Agrobacterium and $E$. coli

\begin{tabular}{lccc}
$\begin{array}{l}\text { Wounded } \\
\text { PLBs }\end{array}$ & $\begin{array}{c}\text { Bacterial } \\
\text { inoculation } \\
\text { time (hours) }\end{array}$ & $\begin{array}{c}\text { Ratio of } \\
\text { Agrobacterium } \\
\text { chemotaxis } \\
\text { movement }\end{array}$ & $\begin{array}{c}\text { Ratio of } \\
\text { E. coli } \\
\text { chemotaxis } \\
\text { movement }\end{array}$ \\
\hline $\mathrm{W}_{1}$ & 24 & $1.09 \pm 0.04^{\mathrm{bc}}$ & $1.04 \pm 0.04^{\mathrm{ab}}$ \\
& 48 & $1.10 \pm 0.02^{\mathrm{abc}}$ & $1.03 \pm 0.07^{\mathrm{ab}}$ \\
$\mathrm{W}_{2}$ & 72 & $1.08 \pm 0.04^{\mathrm{bc}}$ & $1.13 \pm 0.05^{\mathrm{a}}$ \\
& 24 & $1.07 \pm 0.02^{\mathrm{bc}}$ & $0.97 \pm 0.08^{\mathrm{ab}}$ \\
$\mathrm{W}_{3}$ & 48 & $1.27 \pm 0.04^{\mathrm{a}}$ & $1.02 \pm 0.10^{\mathrm{ab}}$ \\
& 72 & $1.23 \pm 0.03^{\mathrm{ab}}$ & $1.05 \pm 0.08^{\mathrm{ab}}$ \\
& 24 & $1.04 \pm 0.04^{\mathrm{c}}$ & $0.82 \pm 0.11^{\mathrm{b}}$ \\
& 48 & $1.03 \pm 0.06^{\mathrm{c}}$ & $0.93 \pm 0.06^{\mathrm{ab}}$ \\
\hline
\end{tabular}

The data represent the mean values \pm standard error. Different letter (s) corresponds to significant differences at $p \leq 0.05$ by Duncan's multiple range tests 

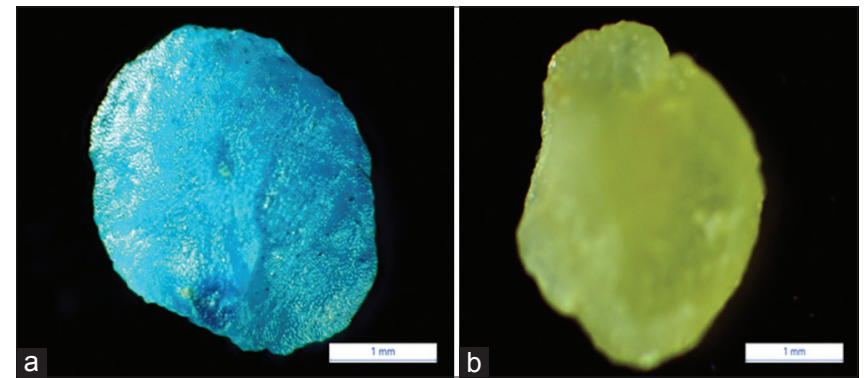

Fig 1. a. Transformed gus $A$ gene expressing PLB and b. Control PLB, bar, $1 \mathrm{~mm}$.

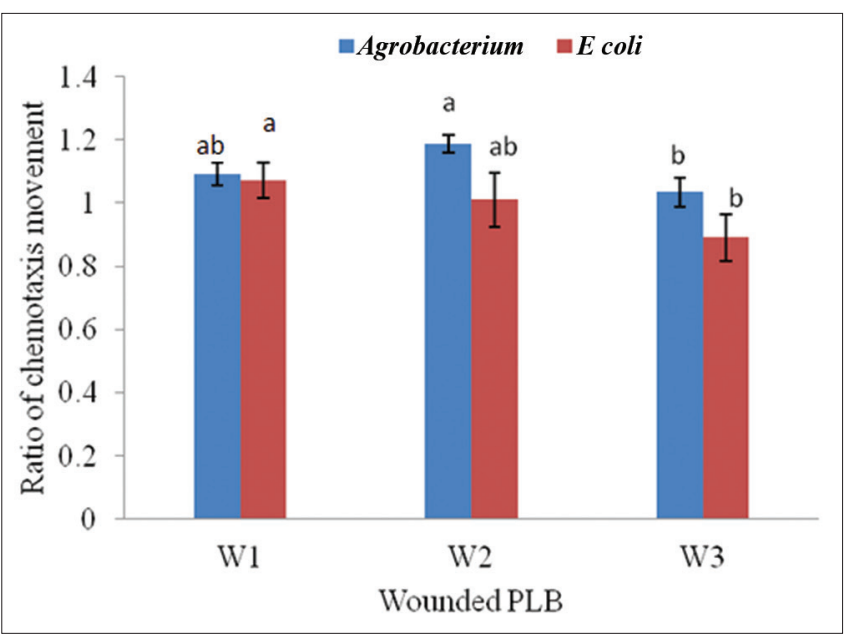

Fig 2. Chemotaxis movement of $A$. tumefaciens strain LBA4404 harbouring the PCAMBIA 1304 and $E$. coli strain $\mathrm{DH} 5 \alpha$ harbouring the pMRC1301 towards different wounded PLBs. $W_{1}=$ Intact PLB, $W_{2}=$ Mild wounded PLB and $\mathrm{W}_{3}=$ Severe wounded PLB.

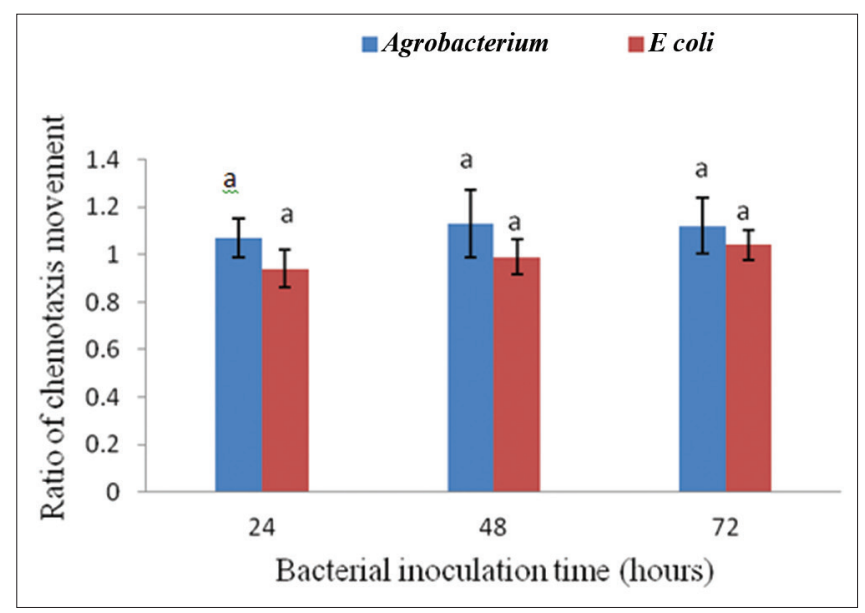

Fig 3. Effect of different time after inoculation on Agrobacterium and E. coli chemotaxis movement of Dendrobium Broga Giant's PLBs.

no significant differences between the bacterial inoculation times (Table 1).

Bacterial single colony cultured on swarm agar plates for swarming outward from the middle point of inoculation and measures the chemotaxis response of E. coli. Three types of wounded PLBs were used in this experiment and chemotaxis responses were determined 24, 48 and 72 hours after inoculation. Wounded PLBs significantly responses on bacterial motility of Dendrobium Broga Giant orchid PLBs (Fig. 2). Fig. 2 showed that the highest (1.06) bacterial motility was determined form intact PLBs $\left(\mathrm{W}_{1}\right)$ whereas the lowest (0.89) and negative chemotaxis responses were recorded in severe wounded PLBs $\left(\mathrm{W}_{3}\right)$. Mild wounded PLBs $\left(\mathrm{W}_{2}\right)$ demonstrated statistically identical bacterial motility on intact PLBs $\left(\mathrm{W}_{1}\right)$ (Fig. 2). Bacterial inoculation time $(24,48$ and 72 hours) did not show any significant differences on the bacterial motility of Dendrobium Broga Giant orchid PLBs (Fig. 3). The maximum (1.04) bacterial motility ratio was observed in 72 hours after inoculations and the minimum (0.94) ratio was recorded from 24 hours after inoculations (Fig. 3). Bacterial (E.coli) inoculation time, 24 hours and 48 hours showed chemotaxis movement negatively (Fig. 3). In combination of wounded PLBs and bacterial inoculation time significantly responded on the bacterial motility of Dendrobium Broga Giant orchid (Table 1). Intact $\left(W_{1}\right)$ PLBs combined with 72 hours after inoculation time demonstrated the highest (1.13) ratio of bacterial motility and the lowest (0.82) ratio was determined in severe wounded PLBs $\left(\mathrm{W}_{3}\right)$ after 24 hours inoculations (Table 1). In all cases, severe wounded PLBs $\left(\mathrm{W}_{3}\right)$ showed the lowest and negative bacterial motility (Table 1). Most of the cases E. coli demonstrated negative responses on DBG orchid PLBs. Bacterial movement accelerated to the PLBs when extra wounding was present in PLBs. Mild wounding PLBs showed more migration of bacteria because mild wounded PLBs secreted more phenolic compounds from wounding site which are accelerated $\operatorname{vir} A$ and $\operatorname{vir} G$. virA and $\operatorname{vin} G$ played a vital role in bacterial chemotaxis (Karami, 2008). Wounded parts of PLBs released acetosyringone which engage in recreation of chemotactic responsibility and encourage the vir genes which initiate T-DNA transfer (Gnasekaran et al., 2014). Similarly, Finer (2010) reported that injured cell of plant parts release acetosyringone which was stimulated virulent genes as well as enhanced T-DNA transfer in cells. Citovsky et al. (2007) reported that Agrobacterium is the first recognize and sense for wounded explants which initiate infection in wounded site of host cells. The Agrobacterium consume nutrient from chemotactic media and slowly migrate outward where inoculate bacteria (Lengeler, 2004). Monica et al. (2011) observed that bacterial chemotaxis initiates bacterial infection towards the plant cells and for this reason beneficial aspect to the host. Julkifle et al. (2012) reported that Agrobacterium showed positive chemotaxis response in Dendrobium sonia-28 orchid PLBs. They also reported that E. coli illustrate negative chemotaxis response on Dendrobium sonia-28 orchid PLBs. Gnasekaran and Subramaniam (2015) also highlighted that Agrobacterium tumefaciens showed positive chemotaxis 
movement on severe wounded Vanda Kasem's Delight orchid PLBs which ratio was 1.46. Gnasekaran et al. (2014) observed that Agrobacterium attached on Aranda Broga Blue orchid PLBs followed by scanning electron microscope (SEM). Gnasekaran and Subramaniam (2015) also pointed out that Agrobacterium attached on Vanda Kasem's Delight orchid protocorm like bodies (PLBs) through SEM.

\section{Wounding of explants}

Three types wounding such as, intact PLBs $\left(\mathrm{W}_{0}\right)$, mild wounding $\left(\mathrm{W}_{1}\right.$, punctured by needle) and severe wounding $\left(\mathrm{W}_{2}\right.$, cell wall removed by scalpel) were used in the experiment. Wounding of explants significantly influenced the transient gus $A$ gene expression of infected PLBs (Fig. 4). The highest transient gus $A$ gene expression $(65.00 \%)$ was found in mildly wounded PLBs $\left(\mathrm{W}_{1}\right)$ and the lowest transient gus $A$ gene expression (40.00\%) was observed in severely wounded PLBs $\left(\mathrm{W}_{2}\right)$ (Fig. 4 and Fig. 10a). Severe wounding allows over infection of Agrobacterium. Hence, the PLBs turned brown due to necrosis. Wounding plays a vital role in Agrobacterium-mediated transformation since it allows the bacterium to infect the target tissue (Finer, 2010). Naturally, acetosyringone released from wounded parts of tissues plays vital role in chemotaxis and induces vir genes to initiate T-DNA transfer (Gnasekaran et al., 2014).

\section{Immersion period}

Different immersion period such as 5, 10, 15, 20, 25 and 30 minutes were used to determine the optimal immersion time for Dendrobium Broga Giant orchid PLBs (Fig. 5). PLBs immersed in Agrobacterium suspension for 15 minutes showed significantly higher transient gus $A$ gene expression percentages $(75.00 \%)$. Increasing the immersion period up to 30 minutes reduced the transient gus $A$ gene expression severely to $18.33 \%$ (Fig. 5 and Fig. 10b). Based on the graphical presentation increasing the immersion period until 15 minutes increased the transient gus $A$ gene expression and a steady decrease in transient gus $A$ gene expression

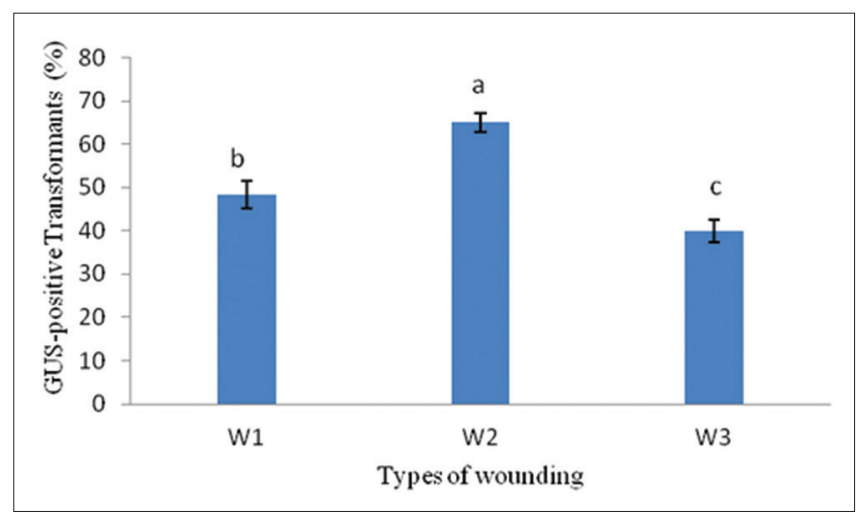

Fig 4. Effect of wounding on transformation efficiency of Dendrobium Broga Giant's PLBs. Error bar correspond to standard error $(\mathrm{N}=180)$. Different letters $(s)$ indicate values are significantly different $(p \leq 0.05)$. is observed from then onwards at 20,25 and 30 minutes. Similarly, PLBs immersed at 30 minutes produced more browning effect on the surface of PLB indicating necrosis due to extreme colonisation of Agrobacterium at longer immersion period. Agrobacterium infection process mainly divided into two steps such as inoculation or immersion and co-cultivation. The time length of which target tissues are immersed in bacterial suspension is called immersion period. Immersion period may differ from few minutes to few hours. Yong et al. (2006) reported that duration of immersion of explants in Agrobacterium suspension enhanced Agrobacterium attachment to the explants. Immersion period varies according to plant species and types of explants (Sreeramanan et al., 2009). For example, leaf midrib of ramie and embryogenic calli of sweet potato immersed in Agrobacterium suspension for 10 minutes (An et al., 2014), generated higher number of gus $A$ positive transformants. However, effectiveness of longer immersion periods such as 30 minutes (Gnasekaran et al., 2014), 40 minutes (Arthikala et al., 2011), 60 minutes (Prashantkumar et al., 2011) or up to 10 hours (Belarmino and Mii, 2000) and even 16 hours (Sundaresha et al., 2010) have been reported in previously.

\section{Co-cultivation periods}

DBG orchid's PLBs were transferred to co-cultivation medium following the immersion process. They were maintained at various co-cultivation periods ranging from 1 to 5 days at interval. After 2 days co-cultivation the maximum transient gus $A$ gene expression $(63.33 \%)$ produced whereas the lowest $(15.00 \%)$ transient gus $A$ positive PLBs were recorded after 5 days of co-cultivation periods (Fig. 6 and Fig. 10c). A steady decrease with significant difference from $63.33 \%$ to $51.67 \%, 26.67 \%$ and $15 \%$ be observed at day 3, 4 and 5 . Similarly, browning of the PLB tissues are very much visible and predominant at day 4 and 5 indicating necrosis due to heavy infection of

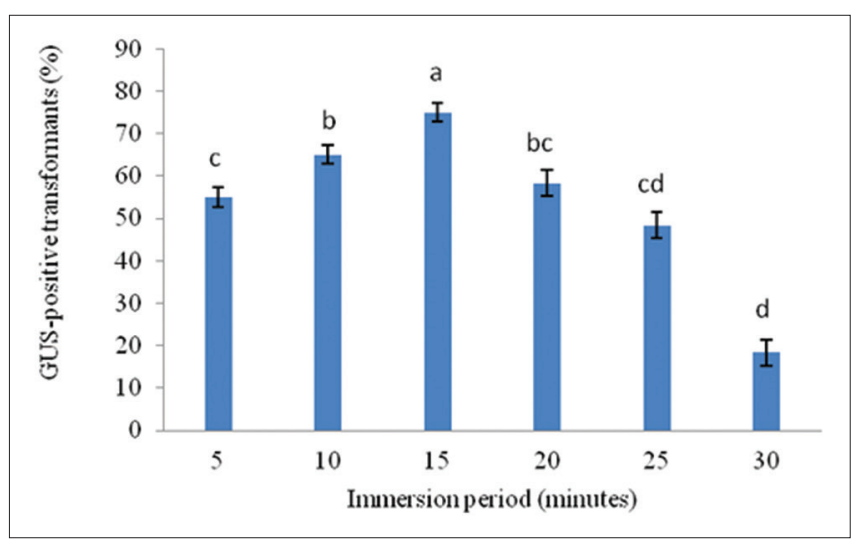

Fig 5. Effect of immersion period on transformation efficiency of Dendrobium Broga Giant's PLBs. Error bar correspond to standard error $(\mathrm{N}=180)$. Different letters $(\mathrm{s})$ indicate values are significantly different $(p \leq 0.05)$. 
Agrobacterium (Fig. 6). However, successful Agrobacteriummediated transformations of plant tissues via employing a longer co-cultivation period have been reported in the previous years. The co-cultivation period of 3 days are optimal for maize (Cho et al., 2014), orchid (Sreeramanan et al., 2010; Gnasekaran et al., 2014), sorghum (Wu et al., 2014) and sugarcane (Kumar et al., 2014). However, 4 days of co-cultivation period for rice (Rahman et al., 2011) or even 5 days in Jatropha curcas (Zong et al., 2010) have been reported previously.

\section{Bacterial optical density (OD at $600_{\mathrm{nm}}$ )}

Various Agrobacterium density tested against Dendrobium Broga Giant (DBG) orchid PLBs significantly influenced the transient gus $A$ gene expression on the treated PLBs. Agrobacterium density of 0.8 at $\mathrm{OD}_{600 \mathrm{~nm}}$ produced the significantly different and highest (68.33\%) transient gus $A$ gene expression on the treated PLBs whereas a density of 1.2 at $\mathrm{OD}_{600 \mathrm{~nm}}$ produced the lowest $(40.00 \%)$ transient gus $A$ gene expression (Fig. 7 and Fig. 10d). Denser bacterial suspension (1 and 1.2 at $\mathrm{OD}_{600 \mathrm{~nm}}$ ) allowed excessive bacterial attachment and therefore caused necrosis on PLB (Fig. 7). Agrobacterium density is one of the key factors

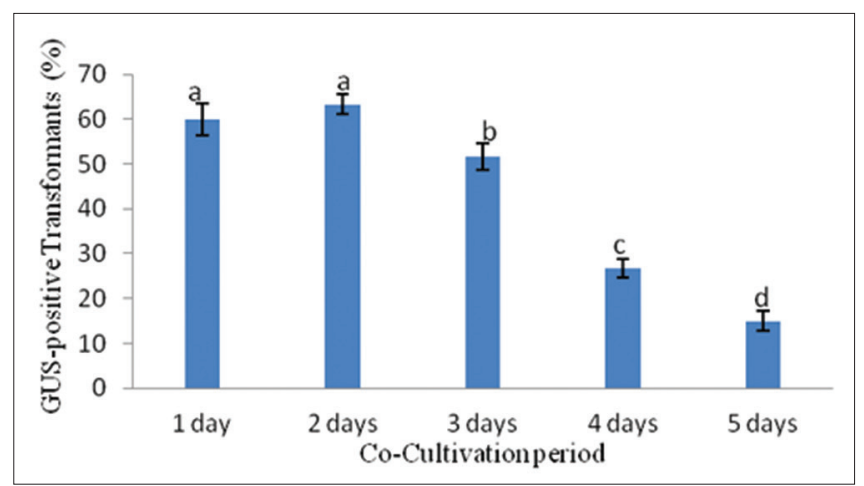

Fig 6. Effect of co-cultivation period on transformation efficiency of Dendrobium Broga Giant's PLBs. Error bar correspond to standard error $(N=180)$. Different letters $(s)$ indicate values are significantly different $(p \leq 0.05)$.

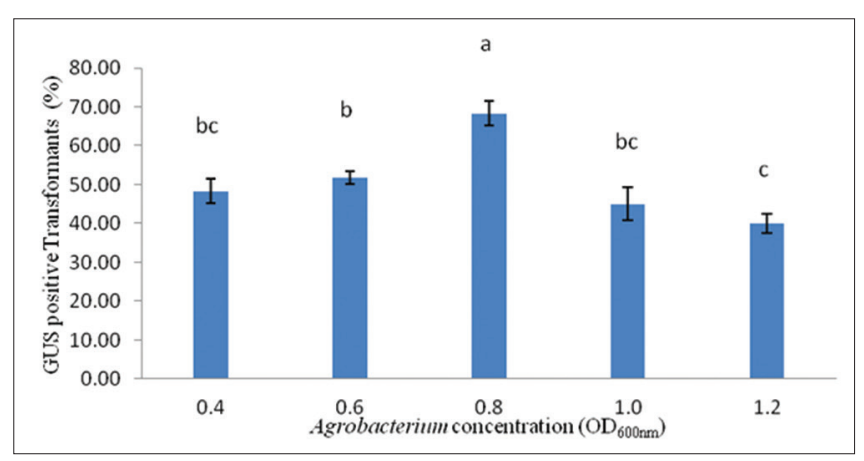

Fig 7. Effect of bacterial concentration (OD600nm) on transformation efficiency of Dendrobium Broga Giant's PLBs. Error bar correspond to standard error $(\mathrm{N}=180)$. Different letters $(\mathrm{s})$ indicate values are significantly different $(p \leq 0.05)$. which affect the transformation frequency (Mishra et al., 2013). Optimal Agrobacterium tumefaciens density will enhance the T-DNA transfer capacity from the bacterium to the host. Similar to the results reported, bacterial density of 0.8 units at $\mathrm{OD}_{600 \mathrm{~nm}}$ were documented to be are optimal for Aspergillus terreus (Wang et al., 2014), banana (Rustagi et al., 2015), and orchid (Gnasekaran et al., 2014). Contrarily, lower density of Agrobacterium suspension at $\mathrm{OD}_{600 \mathrm{~nm}}$ has been recorded to enhance transformation frequency. For example, 0.4 units for tomato (Sivankalyani et al., 2014); 0.5 units for Catharanthus roseus (Weaver et al., 2014) and 0.6 units for garlic (Wang et al., 2011) and ramie (An et al., 2014) have been proved to increase transformation efficiency. However, denser Agrobacterium suspensions have been reported to be optimal bacterial density in previous researches. For example, 0.9 and 1.0 units at $\mathrm{OD}_{600 \mathrm{~nm}}$ were reported to enhance the transformation efficiency of slash pine (Tang et al., 2014) and sugarcane (Kumar et al., 2014).

\section{Acetosyringone concentration}

Acetosyringone is known to significantly improve transformation efficiency in plants (An et al., 2014).

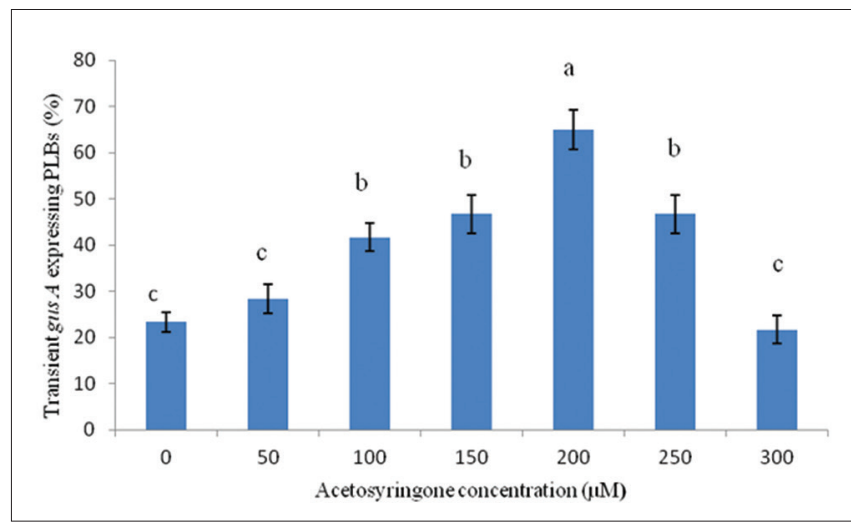

Fig 8. Effect of acetosyringone concentration on transformation efficiency of Dendrobium Broga Giant's PLBs. Error bar correspond to standard error $(\mathrm{N}=180)$. Different letters $(\mathrm{s})$ indicate values are significantly different $(p \leq 0.05)$.
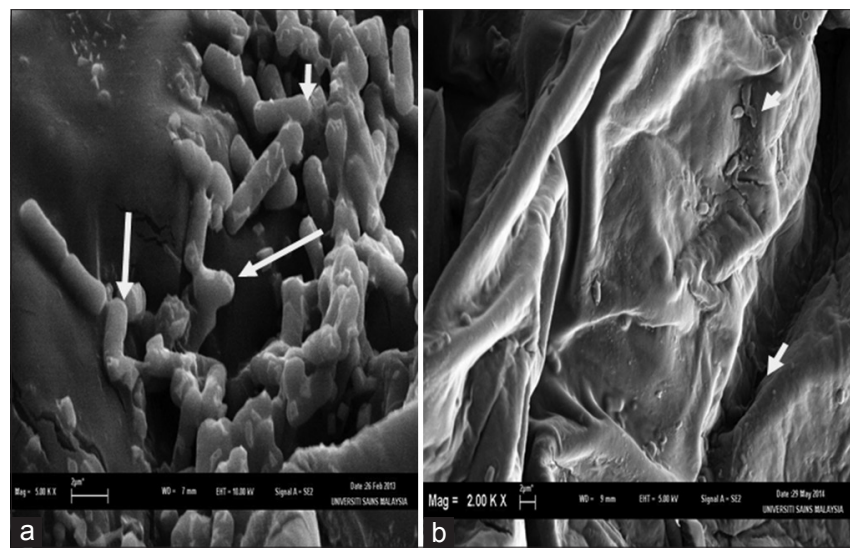

Fig 9. Bacterial attachments on the surface of DBG's PLB. a. Agrobacterium tumefaciens and b. E.coli. 
Therefore, different concentrations of acetosyringone (control, 50, 100, 150, 200, 250 and $300 \mu \mathrm{M}$ ) were tested to improve the Agrobacterium-mediated transformation of DBG orchid's PLBs. Based on the results, PLBs co-cultivated on medium supplemented with $200 \mu \mathrm{M}$ produced the highest percentage $(65.00 \%)$ of transient gus $A$ gene expression (Fig. 8 and Fig. 10e). Although there is no significant difference within control, 50 and $300 \mu \mathrm{M}$ acetosyringone supplemented media, the later produced the lowest transient gus $A$ expression (21.66\%) (Fig.8). Increasing the acetosyringone concentration parallelly increased the transient gus $A$ gene expression gradually and a sharp fall observed on the transient gus $A$ gene expression among PLBs challenged to 250 and $300 \mu \mathrm{M}$ acetosyringone (Fig. 8). These results prove that higher concentrations of acetosyringone are not suitable for Agrobacterium-mediated transformation due to high mortality of DBG PLBs. Hence, based on the results, $200 \mu \mathrm{M}$ acetosyringone is the optimal concentration to improve the Agrobacterium-mediated transformation of DBG PLBs. Agrobacterium tumefaciens attached on PLB surface clearly seen polarly and laterally, under the SEM-scanning electron microscope (Fig. 9a) whereas E. coli attached very few on PLB surface (Fig. 9b). Agrobacterium tumefaciens adhered to the PLB surface and create larger bacterial clusters (Fig. 9a). Agrobacterium cells

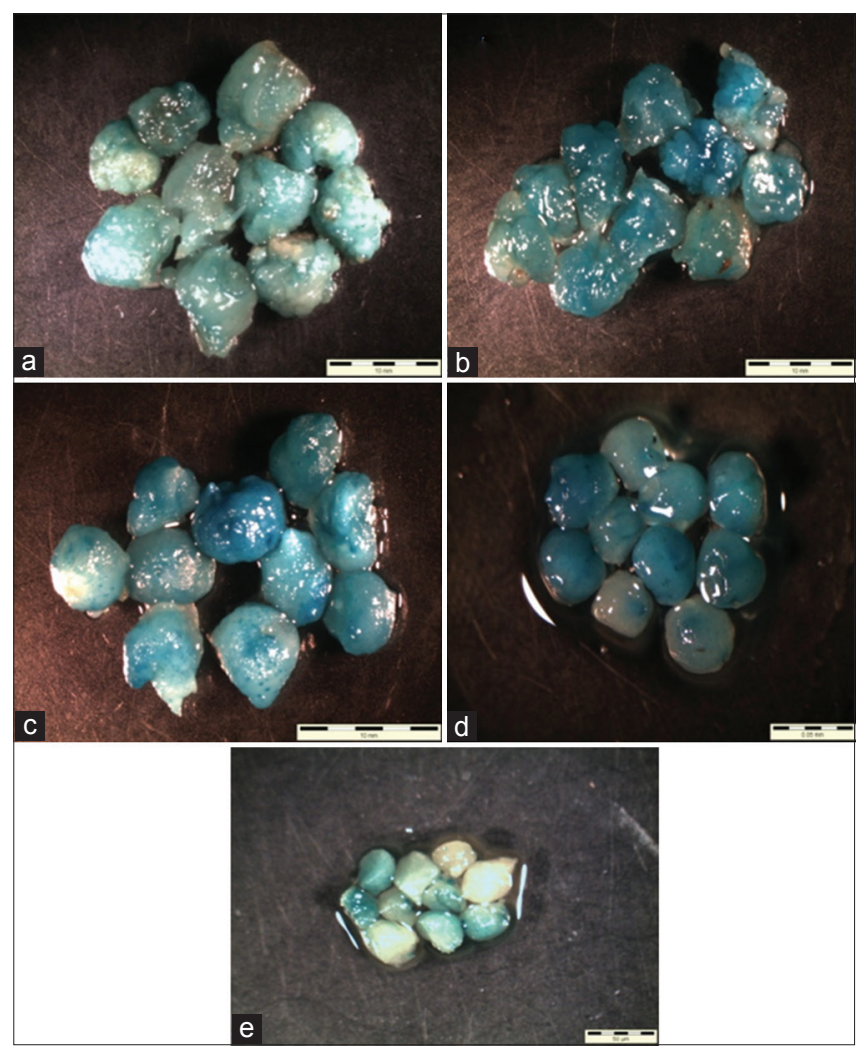

Fig 10. Transient gus A expression of Dendrobium Broga Giant's PLBs. a. Mild wounded PLBs b. 15 minutes immersed PLBs, c. 2 days cocultivated PLBs, d. Agrobacterium density (at $600 \mathrm{~nm}$ ) 0.8 maintained PLBs and e. $200 \mu \mathrm{M}$ acetosyringone treated PLBs. individually bound to the PLB surface polarly especially on trichome and no cellulosic fiber was seen to hold the Agrobacterium cells (Fig. 9a). This indicates that Agrobacterium cells flagellated at the opposite pole for swimming to allow motility while the other pole is bold to permit attachment to surfaces. In addition, SEM observed that Agrobacterium were surrounded by cellulosic fibrillar material (Fig. 9a). The fibrillar-material was produced by the Agrobacterium attached to the PLB as it was not observed on PLBs infected with E. coli strain DH5a (Fig. 9b). Acetosyringone is a phenolic compound known to induce vir genes (Joubert et al., 2002). Optimal Acetosyringone concentrations may vary from 50 to $400 \mu \mathrm{M}$ for different plant species. The optimal concentration of $200 \mu \mathrm{M}$ of acetosyringone reported for DBG PLBs is also supported by the previous researches on Aspergillus terreus (Wang et al., 2014), tomato (Arshad et al., 2014), and orchid (Gnasekaran et al., 2014). Contrarily, a higher concentration of acetosyringone such as $400 \mu \mathrm{M}$ was documented to be optimal for Miscanthus sinensis (Wang et al., 2014) and pearl millet (Ramadevi et al., 2014). Furthermore, slash pine treated with $50 \mu \mathrm{M}$ acetosyringone (Tang et al., 2014); sugarcane (Kumar et al., 2014) treated with $100 \mu \mathrm{M}$ acetosyringone have also reported to produce high number of transgenic lines.

So, the all transformation factors are an important to assure a successful Agrobacterium-mediated transformation of Dendrobium Broga Giant orchid.

\section{CONCLUSION}

In conclusion, positive chemotaxis movement of Agrobacterium represents the ability of genetic transformation on Dendrobium Broga Giant orchid and transient gus $A$ gene expression capability indicates Dendrobium Broga Giant orchid PLBs are suitable target materials for successful Agrobacterium-mediated transformation studies.

\section{ACKNOWLEDGEMENTS}

The authors are gratefully acknowledges the financial support afforded by the Universiti Sains Malaysia (USM), Penang, Malaysia through the USM- Research University grant (1001/PB10L0G1/811211), the TWAS-USM Fellowship and the Sher-e-Bangla Agricultural University, Bangladesh.

\section{Author contributions}

Jasim Uddain made a major contribution in paper writing, data collection and overall planning of the study. Sreeramanan Subramaniam supervised the research and reviewed the paper. Latiffah Zakaria and Chew Bee Lynn were helped for planning of the study. 


\section{REFERENCES}

Ahmad, Z., S. Ariffin, R. A. A. Ramli, M. N. Basiran and A. A. Hassan. 2010. Mutation Breeding Project, Technical material. Publishing Forum for Nuclear Cooperation in Asia (FNCA), New Delhi, Pp. 13-32.

An, X., B. Wang, L. Liu, H. Jiang, J. Chen, S. Ye, L. Chen, P. Guo, X. Huang and D. Peng. 2014. Agrobacterium-mediated genetic transformation and regeneration of transgenic plants using midribs as explants in ramie [Boehmeria nivea (L) Gaurd]. Mol. Biol. Rep. 41: 3257-3269.

Arshad, W., I. Haq, M. T. Waheed, K. S. Mysore and B. Mirza. 2014. Agrobacterium-mediated transformation of tomato with rolB gene results in enhancement of fruit quality and foliar resistance against fungal pathogens. Plos One. 9(5): 1-11.

Arthikala, M. K., K. N. Reddy, M. Manjulatha, E. S. Arellano, R. Sreevathsa and G. Ganeshan. 2011. A rapid and high-throughput identification of putative bell pepper transformants generated via in planta approach. Sci. Hort. 129: 898-903.

Awan, M. F., M. A. Abbas, A. Muzaffar, A. Ali, B. Tabassum, A. Q. Rao, I. A. Nasir and T. Husnain. 2015. Transformation of insect and herbicide resistance genes in cotton (Gossypium hirsutum L.). J. Agric. Sci. Technol. 17: 275-285.

Belarmino, M. M. and M. Mii. 2000. Agrobacterium-mediated genetic transformation of a Phalaenopsis orchid. Plant Cell Rep. 19: 435-442.

Bren, A. and M. Eisenbach. 2000. How signals are heard during bacterial chemotaxis: Protein-protein interactions in sensory signal propagation. J. Bacteriol. 182: 6865-6873.

Cho, M. J., E. Wu, J. Kwan, M. Yu, J. Banh, W. Linn, A. Anand, Z. Li, S. TeRonde, J. C. Register $3^{\text {rd }}$, T. J. Jones and Z. Y. Zhao. 2014. Agrobacterium-mediated high-frequency transformation of elite commercial maize (Zea mays L.) inbred line. Plant Cell Rep. 33: 1767-1777.

Citovsky, V., S. V. Kozlovsky, B. Lacroix, A. Zaltsman, M. Dafny Yelin, S. Vyas, A. Tovkach and T. Tzfira. 2007. Biological systems of the host cell involved in Agrobacterium infection. Cell. Microbiol. 9(1): 9-20.

Finer, J. J. 2010. Plant Nuclear Transformation "Genetic Modification of Plants, Biotechnology in Agriculture and Forestry". Springer, Dordrecht, Pp. 3-21.

Gnasekaran, P., M. N. Mustaffa, J. Uddain and S. Subramanium. 2014. Micromorphological analysis of Aranda broga blue orchid PLBs for Agrobacterium-mediated transformation system. Malaysian J. Microbiol. 10: 186-196.

Gnasekaran, P., J. J. A. Jessica, J. Uddain and S. Sreeramanan. 2014. Agrobacterium-mediated transformation of the recalcitrant Vanda Kasem's delight orchid with higher efficiency. Sci. World J. 2014: 1-10.

Gnasekaran, P. and S. Sreeramanan. 2015. Mapping of the interaction between Agrobacterium tumefaciens and Vanda Kasem's delight orchid protocorm - Like bodies. Indian J. Microbiol. 55: 285-291.

Hossain, M. M., M. Sharma, J. A. Teixeira da Silva and P. Pathak. 2010. Seed germination and tissue culture of Cymbidium giganteum Wall. Ex. Lindl. Sci. Hortic. 123: 479-487.

Joubert, P., D. Beaupère, P. Lelièvre, A. Wadouachi, R. S. Sangwan and B. S. Sangwan Norreel. 2002. Effects of phenolic compounds on Agrobacterium vir genes and gene transfer induction-a plausible molecular mechanism of phenol binding protein activation. Plant Sci. 162: 733-743.

Julkifle, A. L., R. Samian, P. Ranjetta and S. Sreeramanan. 2012. Chemotactic movement and bacterial attachment of
Agrobacterium tumefaciens towards protocorm - like bodies (PLBs) of Dendrobium Sonia 28. Aust. J. Crop Sci. 6: 1188-1191.

Karami, O. 2008. Factors affecting Agrobacterium-mediated transformation of plants. Transgenic Plant J. 2: 127-137.

Khan, M. Y., S. Aliabbas, V. Kumar and S. Rajkumar. 2009. Recent advances in medicinal plant biotechnology. Indian J. Biotechnol. 8: 9-22.

Khan, S., F. Al-Qurainy and M. Nadeem. 2012. Biotechnological approaches for conservation and improvement of rare and endangered plants of Saudi Arabia. Saudi J. Biol. Sci. 19: 1-11.

Kumar, T., Uzma, M. R. Khan, Z. Abbas and G. M. Ali. 2014. Genetic improvement of sugarcane for drought and salinity stress tolerance using Arabidopsis vacuolar pyrophosphatase (AVP1) gene. Mol. Biotechnol. 56: 199-209.

Lengeler, J. W. 2004. Chemotaxis: A Basic and Universal Phenomenon Among Microorganisms and Eukaryotic Cells. Imperial College Press, United Kingdom, Pp. 7-50.

Lux, R. and W. Shi. 2004. Chemotaxis-guided movements in Bacteria. Crit. Rev. Oral. Biol. Med. 15: 207-220.

Merritt, P. M., T. Danhorn and C. Fuqua. 2007. Motility and chemotaxis in Agrobacterium tumefaciens surface attachment and biofilm formation. J. Bacteriol. 189: 8005-8014.

Mishra, S., R. S. Sangwan, S. Bansal and N. S. Sangwan. 2013. Efficient genetic transformation of Withania coagulans (Stocks) Dunal mediated by Agrobacterium tumefaciens from leaf explants of in vitro multiple shoot culture. Protoplasma. 250: 451-458.

Monica, D., C. L. Keng, S. R. S. A. Syarifah, M. Mahmood and S. Sreeramanan. 2011. Chemotaxis movement assay of Eurycoma longifolia using wild and disarmed strains of Agrobacterium rhizogenes. J. Med. Plants Res. 5: 1405-1410.

Murashige, T. and F. Skoog. 1962. A revised medium for rapid growth and bioassays with tobacco tissue cultures. Physiol. Plant. 15: 473-97.

Prashantkumar, S. H., V. R. Sashidhar, M. A. Sushma and S. Rohini. 2011. Improvement of salt tolerance in putatively transgenic rice plants over expressing AVP1, avacuolar $\mathrm{H}+$-pyrophosphatase. Trans. Plant J. 5: 43-49.

Rahman, Z. A., Z. A. Seman, N. Basirun, A. L. Julkifle, Z. Zainal and S. Subramaniam. 2011. Preliminary investigations of Agrobacterium-mediated transformation in indica rice MR 219 embryogenic callus using gus A gene. Afr. J. Biotechnol. 10: 7805-7813.

Ramadevi, R., V. Rao and V. D. Reddy. 2014. Agrobacterium tumefaciens-mediated genetic transformation and production of stable transgenic pearl millet (Pennisetum glaucum [L.]) In Vitro Cell. Dev. Biol. Plant 50: 392-400.

Rustagi, A., S. Jain, D. Kumar, S. Shekhar, M. Jain, V. Bhat and N. B. Sarin. 2015. High efficiency transformation of Banana [Musa acuminate L. cv. Matti (AA)] for enhanced tolerance to salt and drought stress through over expression of a peanut salinityinduced pathogenesis-related class 10 protein. Mol. Biotechnol. 57: $27-35$

Shaw, C. H. 1995. Agrobacterium tumefaciens chemotaxis protocols. In: Gartland, K. M. A. and M. R. Davey (Eds.). Agrobacterium Protocols: Methods in Molecular Biology. Vol. 44. Humana Press Inc., Totowa, NJ, Pp. 29-36.

Sivankalyani, V., S. Takumi, S. Thangasamy, K. Ashakiran and S. Girija. 2014. Punctured-hypocotyl method for high-efficient transformation and adventitious shoot regeneration of tomato. Sci. Horticult. 165: 357-364.

Sreeramanan, S., M. Maziah, M. P. Abdullah, M. Sariah and R. Xavier. 2006. Transient expression of gus $A$ and gfp gene in 
Agrobacterium - mediated banana transformation using tiny meristematic bud. Asian J. Plant Sci. 5: 468-480.

Sreeramanan, S., B. Vinod, P. Ranjetta, S. Sasidharan and R. Xavier. 2009. Chemotaxis movement and attachment of Agrobacterium tumefaciens to Phalaenopsis violacea orchid tissues: An assessment of early factors influencing the efficiency of gene transfer. Trop. Life Sci. Res. 20: 39-49.

Sreeramanan, S. and R. Xavier. 2010. Emerging factors that influence efficiency of T-DNA gene transfer into Phalaenopsis violacea orchid via Agrobacterium tumefaciens-mediated system. Int. J. Biol. 2: 64-73.

Sundaresha, S., A. M. Kumar, S. Rohini, S. A. Math, E. Keshamma, S. C. Chandrashekar and M. Udayakumar. 2010. Enhanced protection against two major fungal pathogens of groundnut, Cercospora arachidicola and Asperigillus flavus in trans-genic groundnut over-expressing a tobacoo ß 1-3 gluconase. Eur. J. Plant Pathol. 126: 497-508.

Tans-Kersten, J., H. Huang and C. Allen. 2001. Ralstonia solanacearum needs motility for invasive virulence on tomato. J. Bacteriol. 183: 3597-3605.

Tang, W., B. Xiao and Y. Fei. 2014. Slash pine genetic transformation through embryo cocultivation with $A$. tumefaciens and transgenic plant regeneration. In Vitro Cell. Dev. Biol. Plant. 50: 199-209.

Terry, K., S. M. Williams, L. Connolly and K. M. Ottemann. 2005. Chemotaxis plays multiple roles during Helicobacter pylori animal infection. Infect. Immun. 73: 803-811.

Teixeira da Silva, J. A., D. P. Chin, P. T. Van and M. Mii. 2011.
Transgenic orchids. Sci Hort. 130: 673-680.

Weaver, J., S. Goklany, N. Rizvi, E. J. Cram and C. W. T. LeeParsons. 2014. Optimizing the transient fast Agro-mediated seedling transformation (FAST) method in Catharanthus roseus seedling. Plant Cell Rep. 33: 89-97.

Wang, H. H., C. T. Wang, H. Liu, R. J. Tang and H. X. Zhang. 2011. An efficient Agrobacterium-mediated transformation and regeneration system for leaf explants of two elite aspen hybrid clones Populus alba $\times$ P. berolinensis and Populus davidiana $\times$ P. bolleana. Plant Cell Rep. 30: 2037-2044.

Wang, D., D. He, G. Li, S. Gao, H. Lv, Q. Shan and L. Wang. 2014. An efficient tool for random insertional mutagenesis: Agrobacterium tumefaciens-mediated transformation of the filamentous fungus Aspergillus terreus. J. Microbiol. Methods. 98: 114-118.

Wu, E., B. Lenderts, K. Glassman, M. Berezowska-Kaniewska, H. Christensen, T. Asmus, S. Zhen, U. Chu, M. J. Cho and Z. Y. Zhao. 2014. Optimized Agrobacterium-mediated sorghum transformation protocol and molecular data of transgenic sorghum plants. In Vitro Cell. Dev. Biol.Plant. 50: 9-18.

Yong, W. T. L., J. O. Abdullah and M. Mahmood. 2006. Optimization of Agrobacterium-mediated transformation parameters for Melastomataceae spp. using green fluorescent protein (GFP) as a reporter. Sci. Horticult. 109: 78-85.

Zong, H., S. Wang, C. Ouyang, X. Deng, L. Li, J. Li and F. Chen. 2010. Agrobacterium-mediated transformation of Jatropha curcas young leaf explants with lateral shoot-inducing factor (LIF). Int. J. Agric. Biol. 12: 891-896. 